Article

\title{
Development of an Optimal Path Algorithm for Construction Equipment
}

\author{
Hak June Lee ${ }^{1}$ and So Young Lim ${ }^{2, *}$ \\ 1 Yooshin Engineering Corporation, Seoul 06252, Korea; dallyhj5@gmail.com \\ 2 School of Architecture, Seoul Nation University of Science \& Technology, Seoul 01811, Korea \\ * Correspondence: isy1120@naver.com
}

Received: 6 May 2020; Accepted: 4 June 2020; Published: 8 June 2020

\begin{abstract}
The fourth industrial revolution based on information and communication technology (ICT and IoT) is converging into the overall realm of technology, economy and society, creating innovative changes. In line with these changes, research is being actively carried out to integrate information and communication with automation at construction sites. This study was started to analyze problems arising from inefficient operation of construction equipment through analysis of risks arising at construction sites and to provide solutions related to these problems. In order to provide the optimal route of movement of construction equipment, an expert survey was conducted and an algorithm was developed to establish the optimal route of movement by analyzing the weights for each item of the survey. The adequacy of the algorithm was determined by comparing the developed algorithm with the actual data of the construction site in operation, and a safe and productive route as well as problems related to invisible safety are provided through the developed algorithm. Applying the optimal-route-generation algorithm conducted in this study to the construction site will not only increase productivity within the workplace, but also ultimately save time in operating equipment and increase safety.
\end{abstract}

Keywords: optimal path; dump; construction; algorithm; terrain; modeling; safety

\section{Introduction}

Korea's construction industry is one step behind in applying new technologies compared to other industrial sectors. In general industries, it is easy to increase work efficiency by introducing equipment with high-efficiency new technologies and applying improved processes through productivity analysis of repetitive tasks or applying new technologies such as automation to production activities, as they are mainly produced indoors, such as in factories.

In the construction industry however it is difficult for skilled engineers to proceed with the project based solely on their previous experience, as all projects begin in an environment where they first experience it. Depending on the changing environment (weather, soil, underground obstacles, etc.) of the industrial site, a new process suitable for it must be established and carried out. For this reason, it is difficult to apply new technologies such as AI to the construction industry, which utilizes accumulated information that has recently been in the spotlight.

However, in the construction industry, many countries are moving to introduce new technologies for the fourth industry. In the design stage, BIM (Building Information Modeling), which contains object information on terrain and structures, rather than the existing 2D method, is being applied to the construction industry in a systematic way, such as presenting models for design and application.

However, it is difficult to design and construct using the new technology because the application of the technology of the fourth industry is not fully reflected in the reality of Korea during the actual design and construction stages. In addition, in the design, construction management, operation, 
and maintenance stages, professional engineers are utilized to carry out the project, but in the construction phase, which accounts for the highest cost in the entire life cycle of the structure, professional engineers are involved only in construction management for the purpose of reducing construction costs, and in actual construction, many kinds of construction equipment and day jobs with relatively low educational levels are utilized. It is difficult to create skilled workers in utilizing day laborers and using the new technology to construct them is a real risk.

In order to address such risks, an intuitive system that can be understood at any stage of design, construction, construction management, operation, and maintenance must be applied to ensure quality and productivity by efficiently operating the previous life cycle of the structure and preventing duplicate work in advance.

Among these problems, this paper presents the optimum movement path algorithm of construction equipment in order to raise the efficiency and safety of construction equipment in the construction stage, and intuitively to the construction equipment driver. In addition, we would like to present the route algorithm to present the optimal route of travel.

\section{Trends of the Technique}

In the case of dump trucks that have a lot of distances, not only in Korea but also abroad, dump truck drivers are guided on their routes by utilizing navigation systems for regular vehicles. Navigation for general vehicles combines the current technology with Virtual Reality (VR) technology, beyond just utilizing Open GIS Map, making it easier for vehicle drivers to present their transportation routes. The existing vehicle navigation system uses the existing road to provide the optimum route by adding factors such as shortest distance, shortest travel time, and traffic conditions, and it also suggests alternative routes for drivers to choose different alternatives. However, construction sites have limitations in using construction equipment that mainly uses the highway to utilize the current navigation system for general vehicles.

There is currently no commercialization model for the presentation of optimal working paths for construction equipment, and the need for development of navigation for presenting optimal routes for construction equipment is emerging.

Christian and Xie (1996) [1] derived factors on transport speed through expert surveys, and Peurifoy and Schexanayder (2005) [2,3] produced graphs that could provide transport speeds, taking into account road conditions and slopes at the actual site based on existing speed data. Marzouk and Moselhi (2004) conducted a qualitative analysis to determine the extent of the effects of factors on the transport speed of construction equipment, and used regression and fuzzy clustering analysis to do so. Park et al. (2007) [4] derived a formula for calculating the speed of dump trucks by examining the density at the intersection of traffic signals, the distance traveled by vehicles, and the amount of traffic per lane. S. Thomas (2008) [5] presented the equipment transport route within the group by grouping the equipment into groups and separating the work of each group.

Choi and Seo (2008) [6] developed an analysis model that takes into account factors such as ground slope, road surface resistance, and ease of maintenance as the factors to analyze the optimum operating path of dump trucks in large-scale open-air mines. Osama (2009) [7] conducted a study to develop an equipment optimization model, while [8] Cheevin (2011) conducted a study to develop a model for optimal equipment combinations through genetic algorithms.

AMR Kandil (2010) [9] studied the optimal path algorithm of the shortest distance criterion [10] Lim et al. (2016) derived the elements for presenting the transport route of construction equipment from the survey of construction equipment drivers and managers, and the weight between the factors was calculated.

Yuling (2017) [11] presented an algorithm for the pathways for each ratio by limiting the renovation of the outer wall of the building. Kim (2017) [12,13], Xin (2018), and others presented the work route by adding elements of the non-workable area during the operation of the site. Lim (2020) [14] and others conducted a study to analyze the productivity of equipment according to the optimal path. 
And, Algorithms for setting the movement path by dividing the equipment into work a studied and presented in various directions. (El-Rayes and Kandil 2005 [15-21]; Hyari and El-Rayes 2006; Kandil and El-Rayes 2006; Lee and Kim 2007; Liu et al. 1997; Liu and Frangopol 2005; Chan and Hu 2002).

To apply these various task-specific algorithms, the algorithm is presented with various factors, mainly using genetic algorithms (GAs). GA was first introduced through Holland (1975) [22], and was applied and used in various fields. GA has developed in various ways, and the engineering use has been developed by applying it in Goldberg (1989) [23,24], El-Rays and Kandil (2005).

Burns et al. (1996) [25,26] conducted a study of algorithms to find optimal alignments by recognizing the path of equipment linearly, while Ipsilandis (2007) conducted a study on the path of movement of various equipment.

\section{Research Scope}

In order to present the optimal route of equipment at the construction stage due to limitations in the use of existing vehicle navigation suitable for construction sites, this paper organizes the necessary elements for moving the equipment through the survey of construction managers and equipment drivers, organizes the necessary factors for each element, enters the weight of each element as variables, forms a grid network, and enters the weight of each grid into the weighted grid at each center of the equipment driver's survey, and calculation optimal grid for as an construction site. The verification of the model derived through simulation is applied to the demonstration site test to verify the developed system.

This paper is divided into two study ranges, as shown in Figure 1.

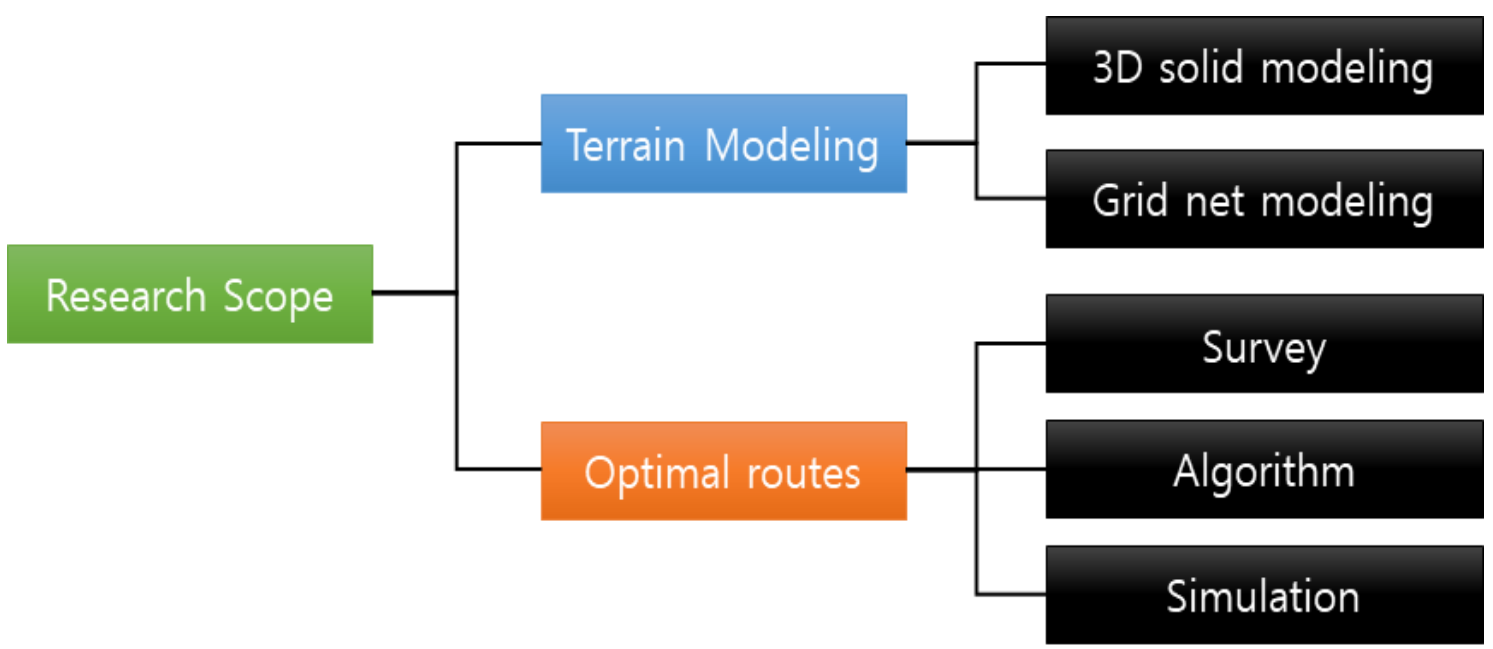

Figure 1. Research Scope.

\subsection{Terrain Modeling}

In general, topographic models show only surface surfaces as data in the form of Surface 2D. However, there is a limit to presenting the optimal route of travel, although it is difficult to identify accurate terrain models with 2D topography. The purpose is to form BIM-based topographical modeling that includes attribute information to present the optimal path of travel and to utilize it as basic data for presenting optimal route of travel. In order to create a BIM terrain model rather than simple terrain modeling by entering attribute information into the terrain model, terrain modeling is carried out using survey elevations, contours, centerlines of roads, buildings, etc., and modeling is formed by separating the target planning ground through design. The reason why models are divided is to present new optimal driving paths for each terrain due to changes in terrain through work due to the characteristics of construction sites. 


\subsection{Optimal Equipment Path Algorithm}

In order to present the optimal equipment movement path, the essential elements in determining the optimal path of the program are divided into essential elements and necessary elements by determining the optimal path of the program by using weights to set weight values for each element, distributing BIM-based terrain, including terrain attribute information, to the grid, analyzing the geometry of each grid through the $\mathrm{x}, \mathrm{y}$, and $\mathrm{z}$ coordinates of each grid, and entering the weighted values in each grid.

\section{Development of the Optimal Equipment Path Algorithm}

\subsection{Calculate the Necessary Elements of the Equipment Path}

It is deemed possible to calculate the most reasonable optimal route by collecting opinions from both the group of managers responsible for the estimation and the group of drivers operating the actual equipment in order to create an algorithm for optimal flow paths of equipment applicable to the actual construction site. In the background of selecting the group, two groups of buyers and actual users were chosen because it was the choice of the field supervisor to determine the equipment and the elements of the equipment due to the characteristics of the construction site in Korea, and the driver was driving along the actual route. The composition of each group's personnel is as follows Table 1.

Table 1. Composition of the Group's members.

\begin{tabular}{cccc}
\hline & Less than $\mathbf{1 0} \mathbf{y}$ & Less than $\mathbf{1 5} \mathbf{y}$ & More than $\mathbf{1 5} \mathbf{y}$ \\
\hline Supervisor & 3 & 12 & 35 \\
\hline Dump Driver & 0 & 22 & 38 \\
\hline Excavator Driver & 5 & 13 & 32 \\
\hline Roader Driver & 3 & 18 & 29 \\
\hline
\end{tabular}

The results of a survey of the factors necessary for the actual equipment movement path to two groups of field supervisors and workers who operate the actual construction equipment shall be as shown in Figures 2 and 3.

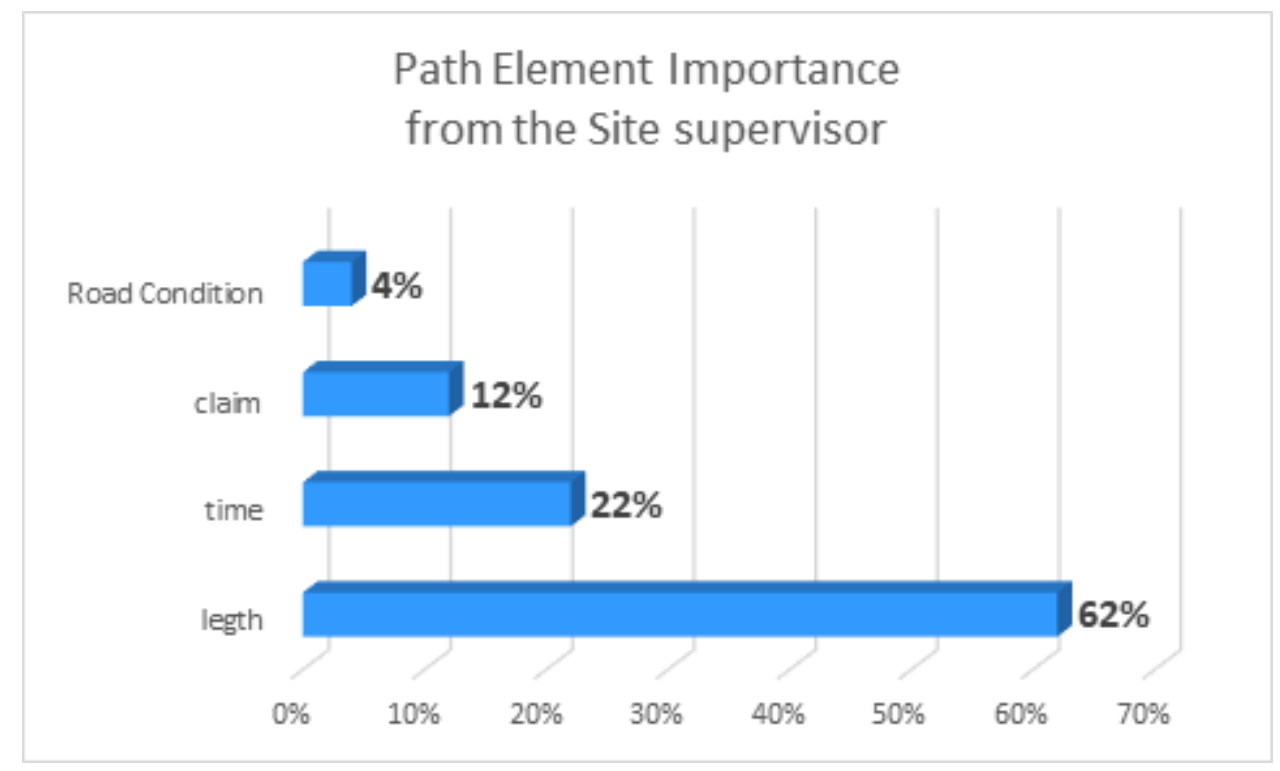

Figure 2. Path element importance from the site supervisor. 


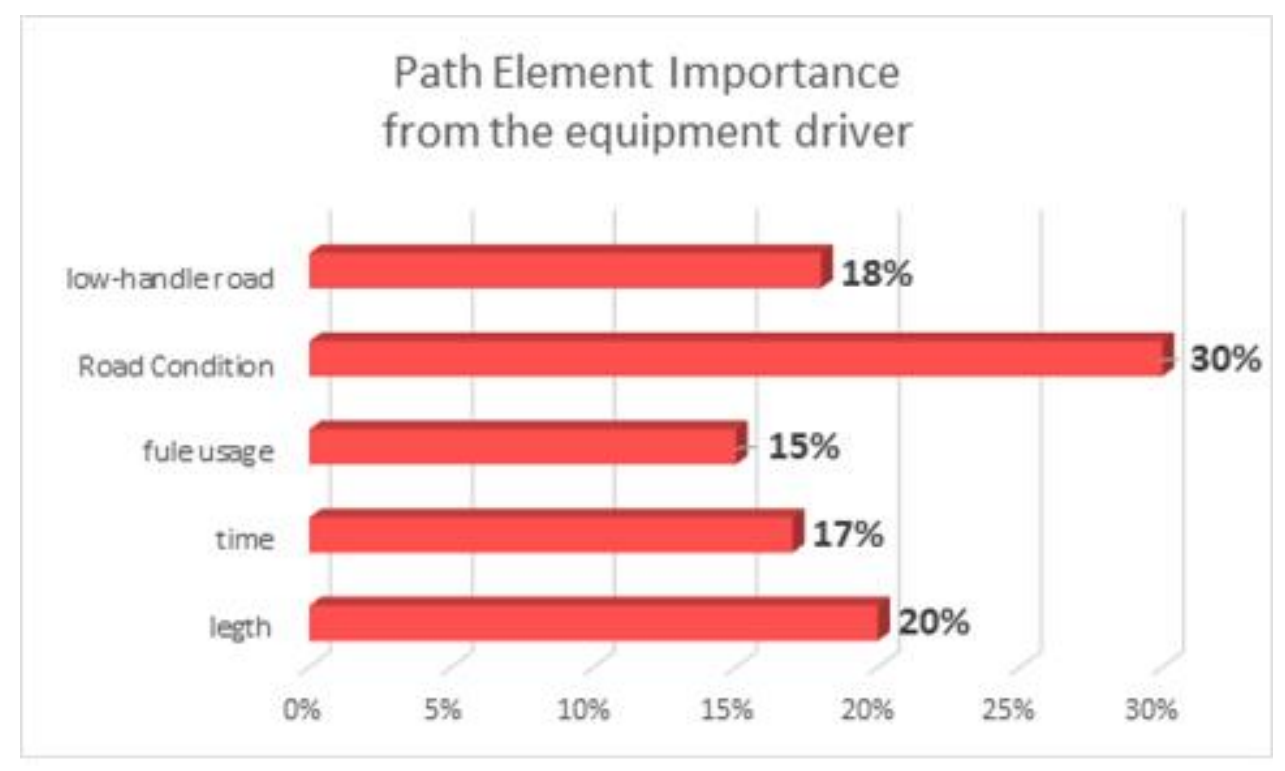

Figure 3. Path element importance from the equipment driver.

The results obtained through the survey showed that the importance factor of the equipment's movement path was different from that of the on-site operator who planned the initial equipment movement path and that of the equipment driver who was operating the actual equipment. Basically, both the distance and time of equipment movement were selected as important factors, and the position of the field supervisor was considered to be more sensitive to the surrounding complaints, and the equipment driver was sensitive to the conditions of roads directly related to safety and the amount of fuel consumption.

In order to set the movement path of equipment, the essential elements and the necessary elements were classified, and the areas where equipment cannot be moved were set as essential elements. Next, equipment drivers and on-site supervisors set weight values in the order in which they need to be considered in setting the movement path of the equipment in order of need, and the relative importance of the factors to be considered in the transport of earthworks was derived as Table 2 by applying the AHP (Animal Hierarchy Process) technique to adjust the set value of the weights.

Table 2. Importance of Cost Elements Pairwise Contrast.

\begin{tabular}{cccccc}
\hline & Length & $\begin{array}{c}\text { Road } \\
\text { Condition }\end{array}$ & $\begin{array}{c}\text { Fuel } \\
\text { Usage }\end{array}$ & Claim & $\begin{array}{c}\text { Operation } \\
\text { Number }\end{array}$ \\
\hline Length & 1.0 & 3 & 3 & 4 & $1 / 2$ \\
\hline Road Condition & $1 / 3$ & 1.0 & 2 & 3 & $1 / 3$ \\
\hline Fuel Usage & $1 / 3$ & $1 / 2$ & 1.0 & 2 & $1 / 2$ \\
\hline Claim & $1 / 4$ & $1 / 3$ & $1 / 2$ & 1.0 & $1 / 5$ \\
\hline Operation number & $1 / 2$ & $1 / 3$ & $1 / 2$ & $1 / 5$ & 1.0 \\
\hline
\end{tabular}

Relative comparison was made by converting the results of the same number of questionnaires into the same number of groups, separated by the actual purchaser and the consumer, and can be applied to the actual site as both the actual buyer and driver needs can be reflected using AHP techniques.

\subsection{Optimal Topographical Modeling}

The terrain model used in the existing design phase consists of a 2D terrain model consisting of points including height values and lines. As the design is carried out by utilizing the terrain model, 
it is impossible to intuitively check the interference of the structure, etc., so the design is conducted depending on the number of profiles and sections, which leads to a decrease in productivity due to changes in the design. In Korea, a national research project under the supervision of the Ministry of Land, Infrastructure and Transport, Fleet Management for Construction Equipment and Technology Smart Construction Using ICT (2018) [27-29], conducted research on the optimal movement path of equipment, and used Dijkstra algorithm to find the shortest route by targeting the main buyer and reflecting the needs of the manager, and set the prohibited zone only. This algorithm suggests the path of equipment except for obstacles, buildings, etc., which is significantly different in terms of fuel efficiency and safety of the equipment, so there is a limit to actual site application. In order to secure this, a topographical model with multiple attribute information must be formed in the existing topographical model.

First, the terrain is modeled by including the terrain coordinates obtained through the measurement, contours, buildings, roads, rivers and lakes all as topographical elements.

The topographical model created through this is created with a 2D surface formed by a plane, not a terrain made up of dots and lines. The reason for not using 3D models using Boring Data Light is that in the case of equipment path modules, equipment operates on the surface, so it has the advantage of minimizing unnecessary data to conduct more accurate and faster analysis of optimal equipment pathways.

Overlay the surface model into a grid measuring $1 \mathrm{~m} \times 1 \mathrm{~m}$ as shown in Figure 4 and then separated. Using the center point for each grid, a tin model is constructed to analyze the slope of the connected grid and it is stored as a property value. In addition, the grid within the boundaries of buildings, rivers, lakes, etc. is changed to a dummy grid that cannot be calculated.

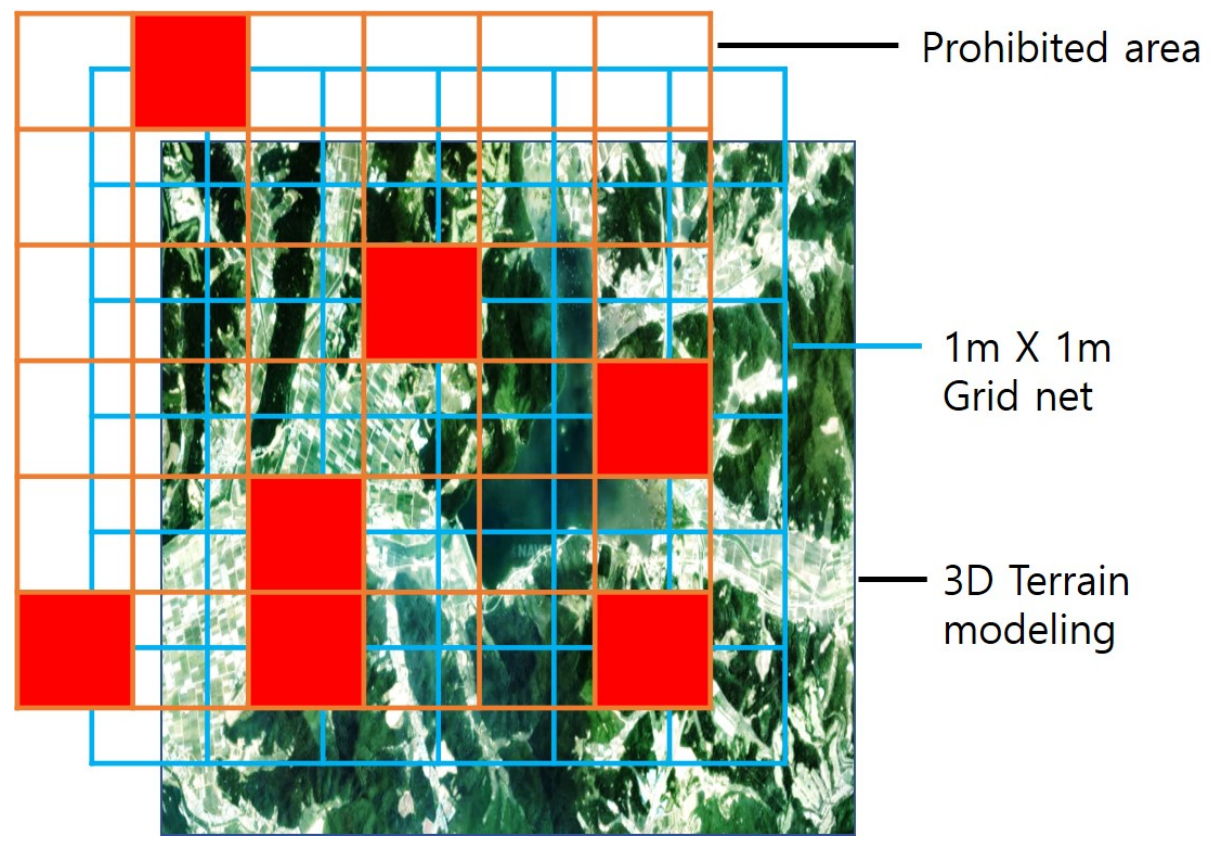

Figure 4. Topographical Modeling with Essential Factors.

In addition, the dummy value is applied to roads with a width of less than $4 \mathrm{~m}$ during road modeling to analyze roads that can be used outside the site for the utilization of existing roads, and the grid's attribute value is analyzed for the purpose of prioritizing wide roads, and the weighting value is included in the higher the width of the roads.

All of these weight values are added together and entered as attribute values in the grid, such as in Figure 5. 


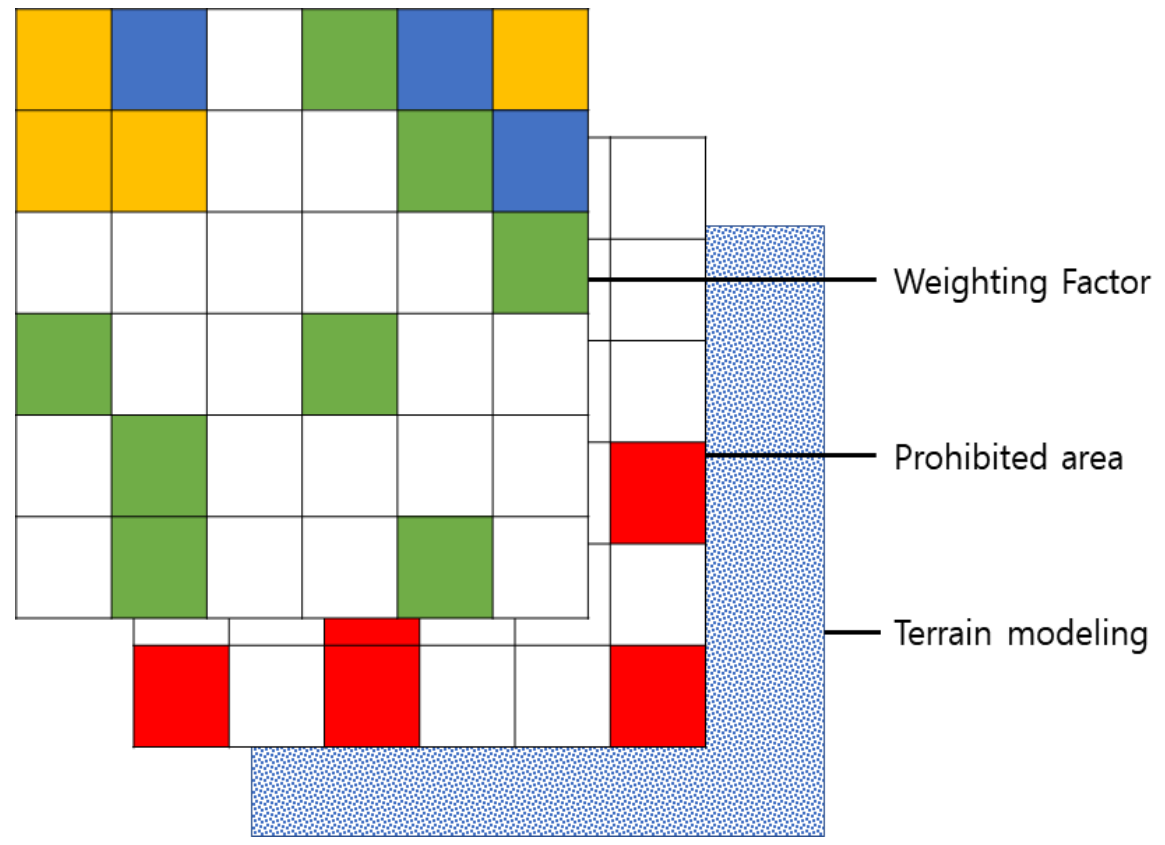

Figure 5. Terrain Modeling with Necessary Factors.

\subsection{Optimal Path Algorithm}

An optimal path algorithm for construction equipment is formed by utilizing a grid containing property values created through topographical models.

The reason why the grid is used instead of using the original terrain model directly is because separating the 2D surface model and adding the attribute value creates a myriad of data and takes a lot of time to analyze the optimal path of the equipment, resulting in less productivity due to the increase in idle time, so, the optimal distance of operation is calculated as $1 \mathrm{~m}$ for each grid and the weighted value of the grid is presented.

The weight of the optimal path algorithm used in this paper is the same as Table 3 made in consideration of the values used in the survey and the existing route plan.

Table 3. Algorithm Weight for Optimal Path Setting.

\begin{tabular}{ccccccc}
\hline \multirow{2}{*}{ Factors } & \multicolumn{5}{c}{ Weighting Value } & \multirow{2}{*}{ Note } \\
\cline { 2 - 6 } & Best & Good & Normal & Bed & Worst & Shortest distance is best \\
\hline Distance & 10 & 9 & 8 & 7 & 6 & Pavement condition \\
\hline Road Condition & 5 & 4 & 3 & 2 & 1 & Under $\pm 20^{\circ}$ \\
\hline Sloping Degree & 8 & 6 & 4 & 2 & 0 & Number of handle operations \\
\hline Fuel Usage & 3 & 2.5 & 2 & 1.5 & 1 & \\
\hline Operation Number & 3 & 2.5 & 2 & 1.5 & 1 & \\
\hline Claim & 6 & 4.5 & 3 & 1.5 & 0 &
\end{tabular}

The reason for the highest weighting of the travel distance among the necessary factors is that it is included as a major factor in the calculation of construction costs from the design stage, which also plays a very sensitive role in the actual site, making the shortest distance among the travel factors a priority. The shortest distance was set in the path excluding dummy using Dijkstra algorithm.

The condition of the road was divided into the following Table 4 and the weighting value was set. 
Table 4. Value for road condition.

\begin{tabular}{ccc}
\hline Road Condition & Average Speed & Value \\
\hline Poor roads such as borrow fit & $7 \mathrm{~km} / \mathrm{h}$ & 1 \\
\hline Hard-to-cross mountain road & $10 \mathrm{~km} / \mathrm{h}$ & 2 \\
\hline Interchangeable unpaved road & $15 \mathrm{~km} / \mathrm{h}$ & 3 \\
\hline Two-lane pavement road & $20 \mathrm{~km} / \mathrm{h}$ & 4 \\
\hline More Two-lane pavement road & $30 \mathrm{~km} / \mathrm{h}$ & 5 \\
\hline
\end{tabular}

Although the terrain on which construction equipment can be equipped can be operated on a relatively high slope compared to passenger cars, the weight was set as shown in Table 5 in order to prevent safety accidents, although the factors were omitted in the survey due to the efficiency and safety problems of the work depending on the slope.

Table 5. Value for sloping degree.

\begin{tabular}{cc}
\hline Sloping Degree & Value \\
\hline $\pm 15^{\circ} \sim 20^{\circ}$ & 0 \\
\hline $\pm 10^{\circ} \sim 15^{\circ}$ & 2 \\
\hline $\pm 5^{\circ} \sim 10^{\circ}$ & 4 \\
\hline $\pm 0^{\circ} \sim 5^{\circ}$ & 6 \\
\hline None & 8 \\
\hline
\end{tabular}

In addition, if the reserved curve is frequent while driving, the driver will feel tired easily due to frequent steering of the steering wheel, the number of steering wheel increases, and the number of steering wheel increases, decreases, such as fuel consumption and speed drops, which are included as an element to present a route with fewer steering wheel movements.

To apply the optimal route algorithm, algorithms including various weights to create the safest and most efficient road at the shortest distance are as follows Table 6 and Algorithm 1.

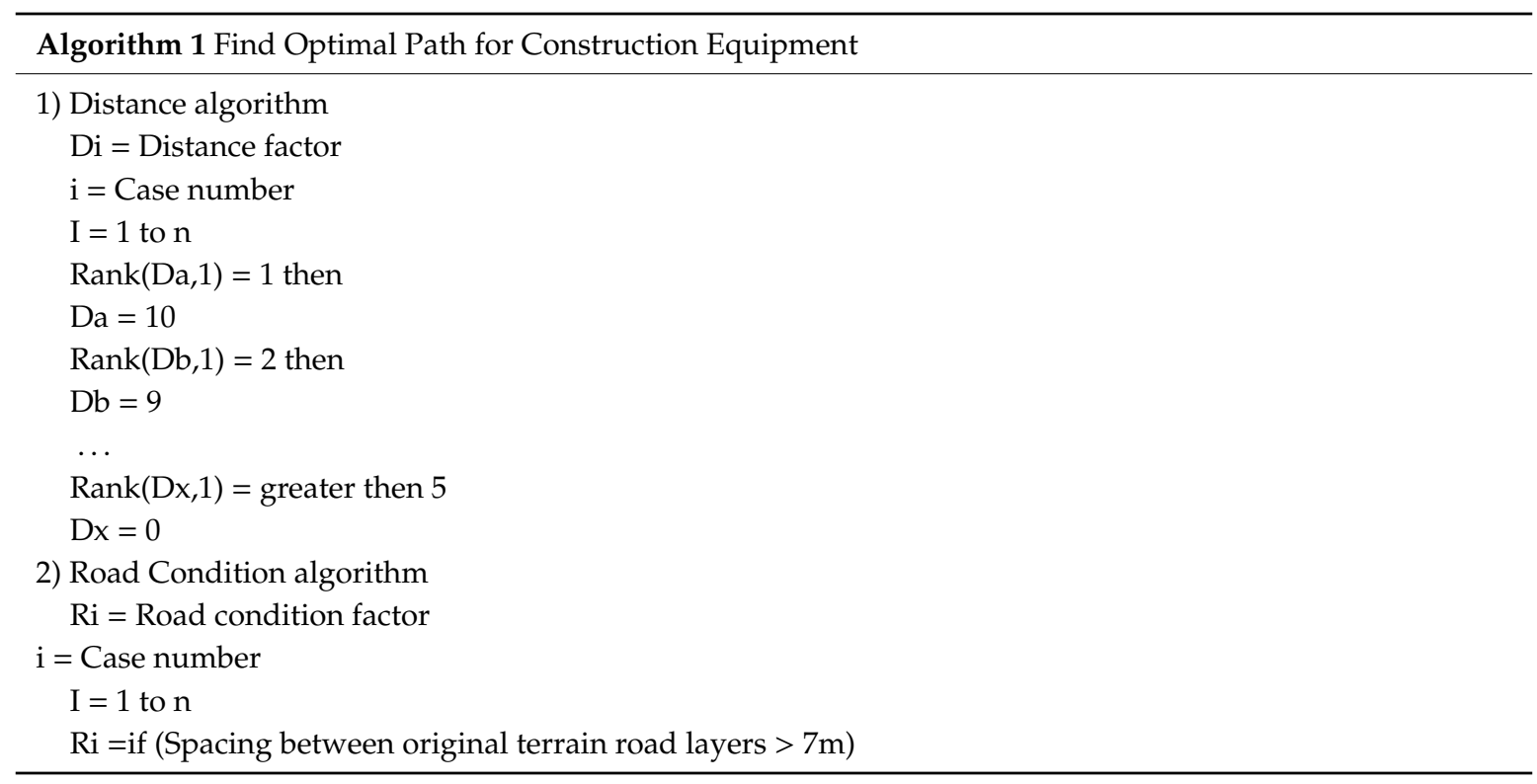


Then $\mathrm{Ri}=5$

Else then if (Spacing between original terrain road layers $>3.5 \mathrm{~m}$ )

Then $\mathrm{Ri}=4$

Else then if(Spacing between design terrain road layers $>3.5 \mathrm{~m}$ )

Then $\mathrm{Ri}=3$

Else then if(Spacing between design terrain road layers $>2 \mathrm{~m}$ )

Then $\mathrm{Ri}=2$

Else $\mathrm{Ri}=1$

3) Slope degree algorithm

$$
\begin{aligned}
& \text { SDi = Slope factor } \\
& \mathrm{i}=\text { Case number } \\
& \mathrm{z}=\text { terrain elevation } \\
& \mathrm{k}=\text { each grid number } \\
& \text { if(SD1 = } \tan ((\mathrm{Z} 1-\mathrm{Z} 2) /(\mathrm{K} 1-\mathrm{k} 2)=0) \\
& \text { then SD1 = } 8 \\
& \text { if }(\mathrm{SD} 1=\tan ((\mathrm{Z} 1-\mathrm{Z} 2) /(\mathrm{K} 1-\mathrm{k} 2)<0.09) \\
& \text { then SD1 = } 6 \\
& \text { if }(\mathrm{SD} 1=\tan ((\mathrm{Z} 1-\mathrm{Z} 2) /(\mathrm{K} 1-\mathrm{k} 2)<0.17) \\
& \text { then SD1 = } \\
& \text { if }(\mathrm{SD} 1=\tan ((\mathrm{Z} 1-\mathrm{Z} 2) /(\mathrm{K} 1-\mathrm{k} 2)<0.27) \\
& \text { then SD1 = } \\
& \text { if(SD1 }=\tan ((\mathrm{Z} 1-\mathrm{Z} 2) /(\mathrm{K} 1-\mathrm{k} 2)<0.36) \\
& \text { then SD1 }=0
\end{aligned}
$$

4) Fuel usage algorithm

$$
\begin{aligned}
& \mathrm{Fi}=\text { Usage factor } \\
& \mathrm{i}=\text { Case number } \\
& \mathrm{I}=1 \text { to } \mathrm{n} \\
& \operatorname{Rank}(\mathrm{Fa}, 1)=1 \text { then } \\
& \mathrm{Fa}=3 \\
& \operatorname{Rank}(\mathrm{Fb}, 1)=2 \text { then } \\
& \mathrm{Fb}=2.5 \\
& \ldots \\
& \operatorname{Rank}(\mathrm{Fx}, 1)=\text { greater then } 5 \\
& \mathrm{Fx}=0
\end{aligned}
$$

5) Number of operation algorithm

$\mathrm{Oi}=$ Operation factor

$\mathrm{i}=$ Case number

$\mathrm{C}=$ operation number

$\mathrm{L}=$ line number between each grid

if $(\mathrm{C} 1=\cos (\mathrm{C} 1 / \mathrm{C} 2) \cos (\mathrm{C} 2 / \mathrm{C} 3)<0)$

$\mathrm{C} 1=0$ else $\mathrm{C} 1=1$

Ci to $n$

$\mathrm{Oi}=\sum_{1}^{n} \mathrm{Cn}$

$\operatorname{Rank}(\mathrm{Oi})=1$

Then Ox $=3$

..

$\operatorname{Rank}(\mathrm{Ox}, 1)=$ greater then 5

$\mathrm{Ox}=0$

6) Claim algorithm

$\mathrm{Ci}=$ Claim factor

$\mathrm{i}=$ Case number 


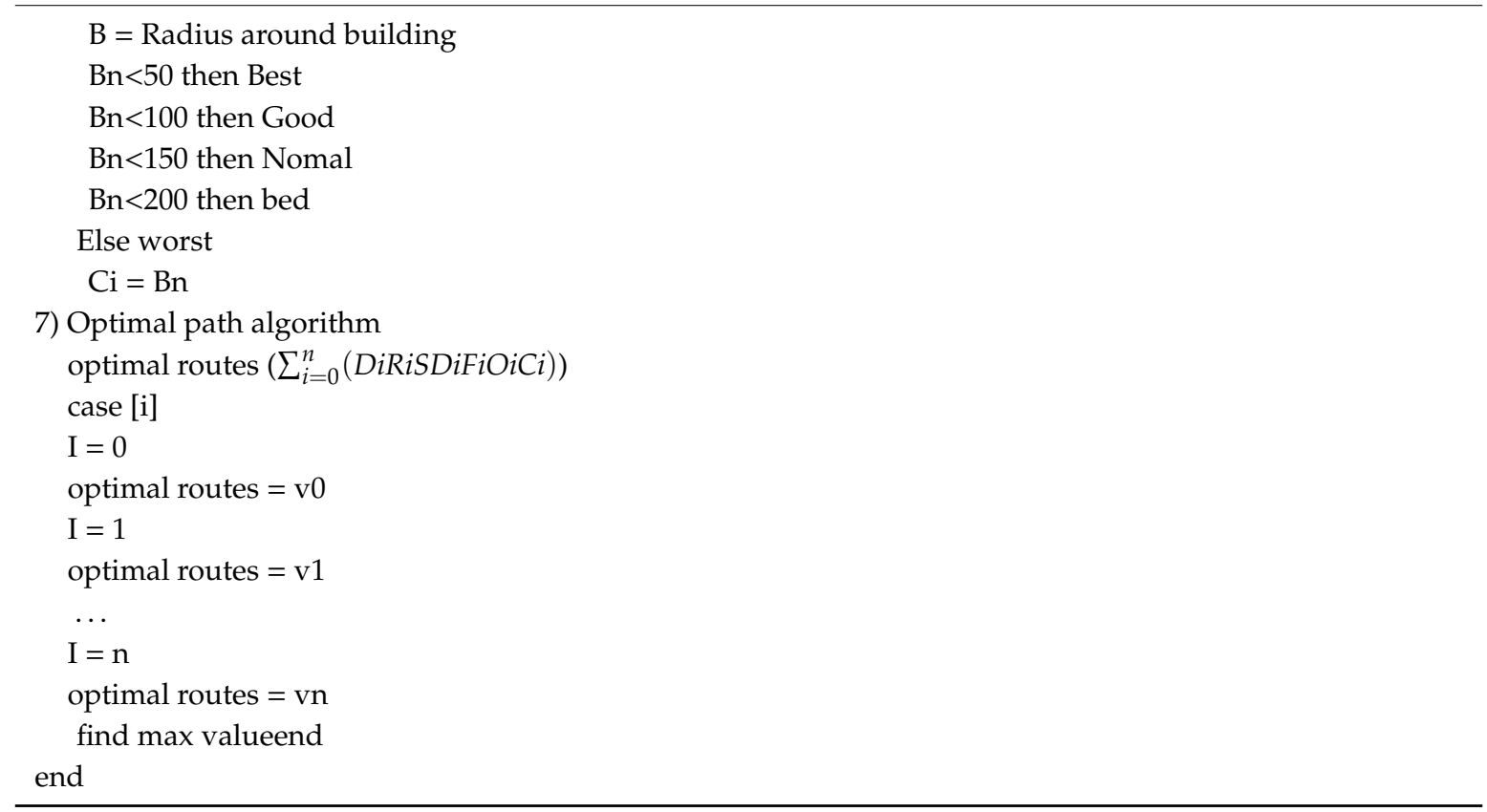

Table 6. List of algorithm symbols.

\begin{tabular}{cc}
\hline Symbol & Meaning \\
\hline $\mathrm{Di}$ & Construction equipment Work Distance \\
\hline $\mathrm{Ri}$ & Road Condition \\
\hline $\mathrm{SDi}$ & Adjacent grid-to-grid slope degree \\
\hline $\mathrm{Fi}$ & Fuel usage by path \\
\hline $\mathrm{Oi}$ & Number of steering wheel operations \\
\hline $\mathrm{Ci}$ & Claim factor during construction \\
\hline
\end{tabular}

\section{Optimal Path Algorithm Appropriateness Review}

We reviewed the appropriateness of the algorithm through dumps with the most movement among construction equipment in operation at the field under construction in Korea.

Lee et al. (2006) [30] conducted a productivity analysis study for each construction equipment work through the construction equipment productivity analysis, and suggested the productivity of dumps as a problem. This study also conducted a limited analysis on dumps as an extension of the study.

First of all, the results of the analysis of the actual movement path of the dumps in operation are as shown in Table 7.

Table 7. Comparing Equipment Paths by Work.

\begin{tabular}{ccccc}
\hline Work & Distance & Slope & Speed & Road Condition \\
\hline$\# 1$ & $10.4 \mathrm{~km}$ & $3^{\circ}$ & $22 \mathrm{~km} / \mathrm{h}$ & Two-lane pavement road \\
\hline$\# 2$ & $8.7 \mathrm{~km}$ & $15^{\circ}$ & $7 \mathrm{~km} / \mathrm{h}$ & Poor roads such as borrow fit \\
\hline$\# 3$ & $15.6 \mathrm{~km}$ & $4^{\circ}$ & $35 \mathrm{~km} / \mathrm{h}$ & More Two-lane pavement road \\
\hline$\# 4$ & $12.1 \mathrm{~km}$ & $6^{\circ}$ & $21 \mathrm{~km} / \mathrm{h}$ & Two-lane pavement road \\
\hline$\# 5$ & $9.8 \mathrm{~km}$ & $12^{\circ}$ & $12 \mathrm{~km} / \mathrm{h}$ & Hard-to-cross mountain road \\
\hline
\end{tabular}


There are five types of tasks, each of which has a different path. In order to set the optimal route for each task, the terrain map as shown in Figure 6, and the prohibited area, which is an essential element set.

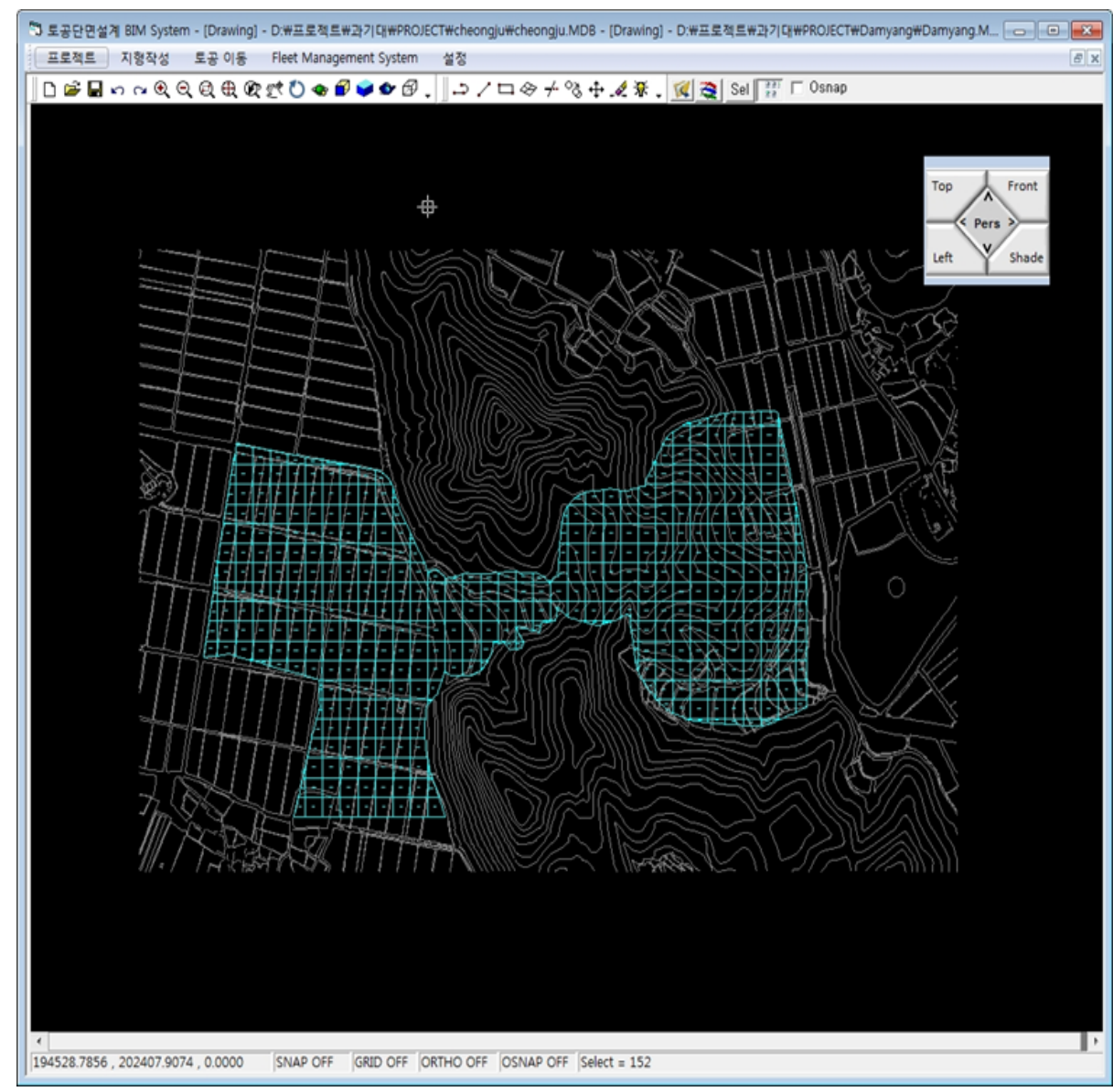

Figure 6. Terrain Modeling with Prohibited Zones.

As shown in Figure 7, the optimal path is set through the optimal path algorithm for each task. 


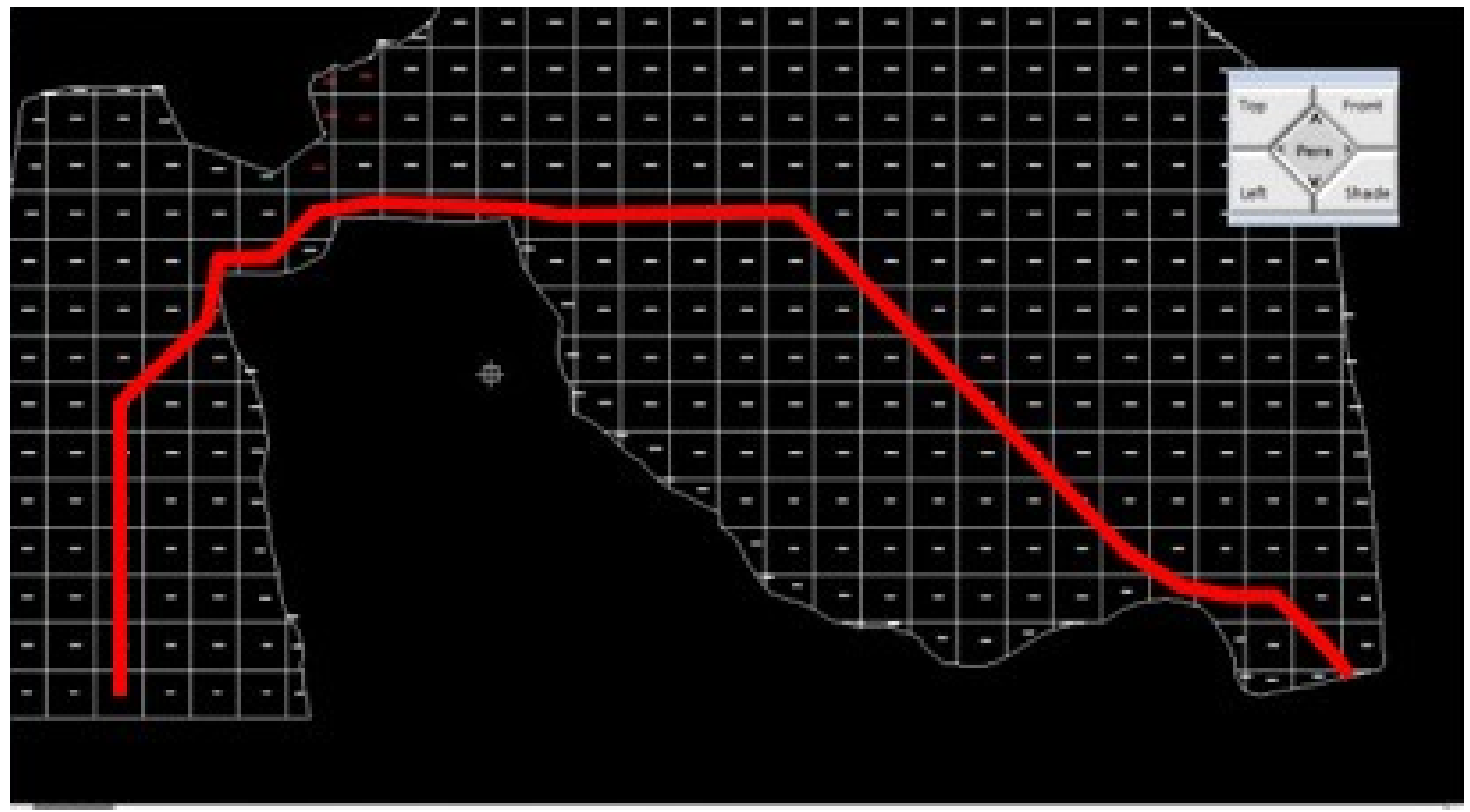

Figure 7. Optimal Path.

The optimal path was compared with the data due to the optimal route and contextual routing by utilizing algorithms. Based on the original data, the paths derived from the optimal path algorithm, the shortest path, the safety path, and the routes with low fuel consumption were compared through simulation.

First of all, the analysis of the path distances of the original data, optimal path, shortest path, safety path, and low fuel consumption path for each task is as follows (Figure 8).

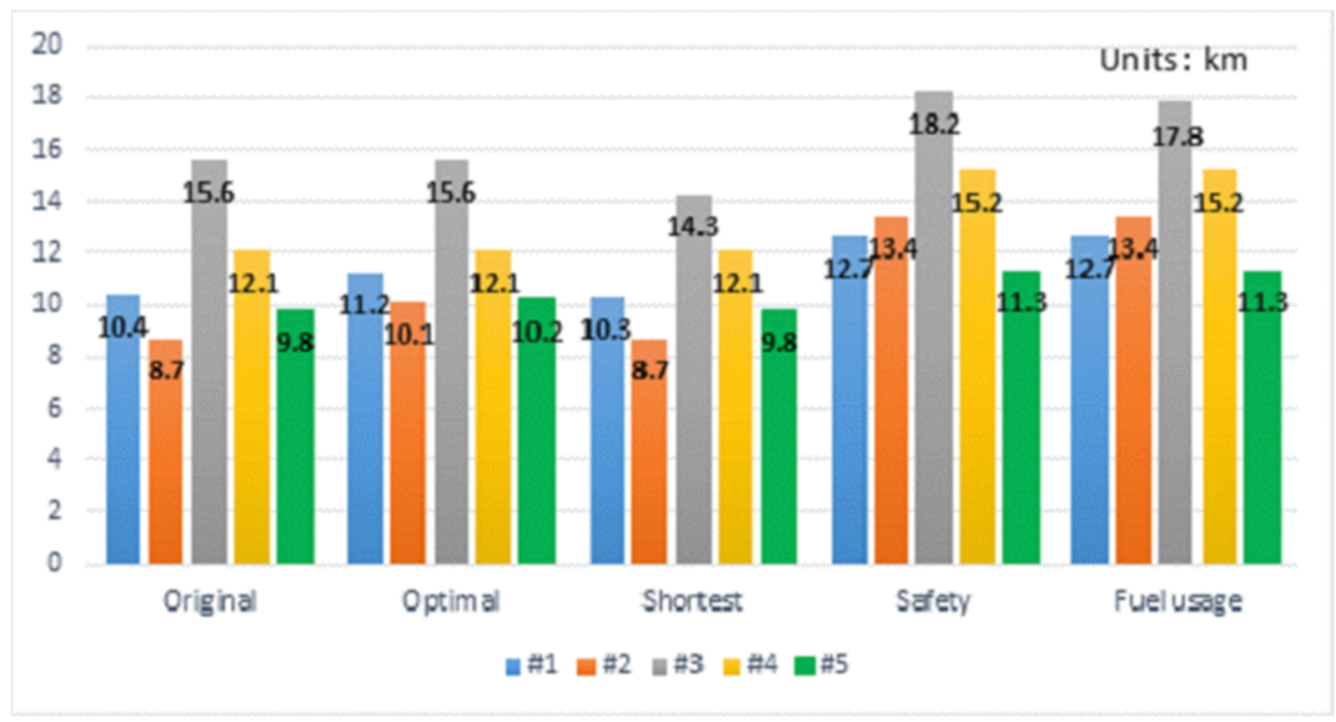

Figure 8. Compare path distance.

The routes show different indicators for different tasks. Some paths were the same as the shortest, and others had the same value as the actual data. However, the road with good fuel efficiency, which allows the choice of a safe route and a good road considering the slope first, has a longer distance to travel compared to other routes.

The average slope by job and by route is as shown in Figure 9. 


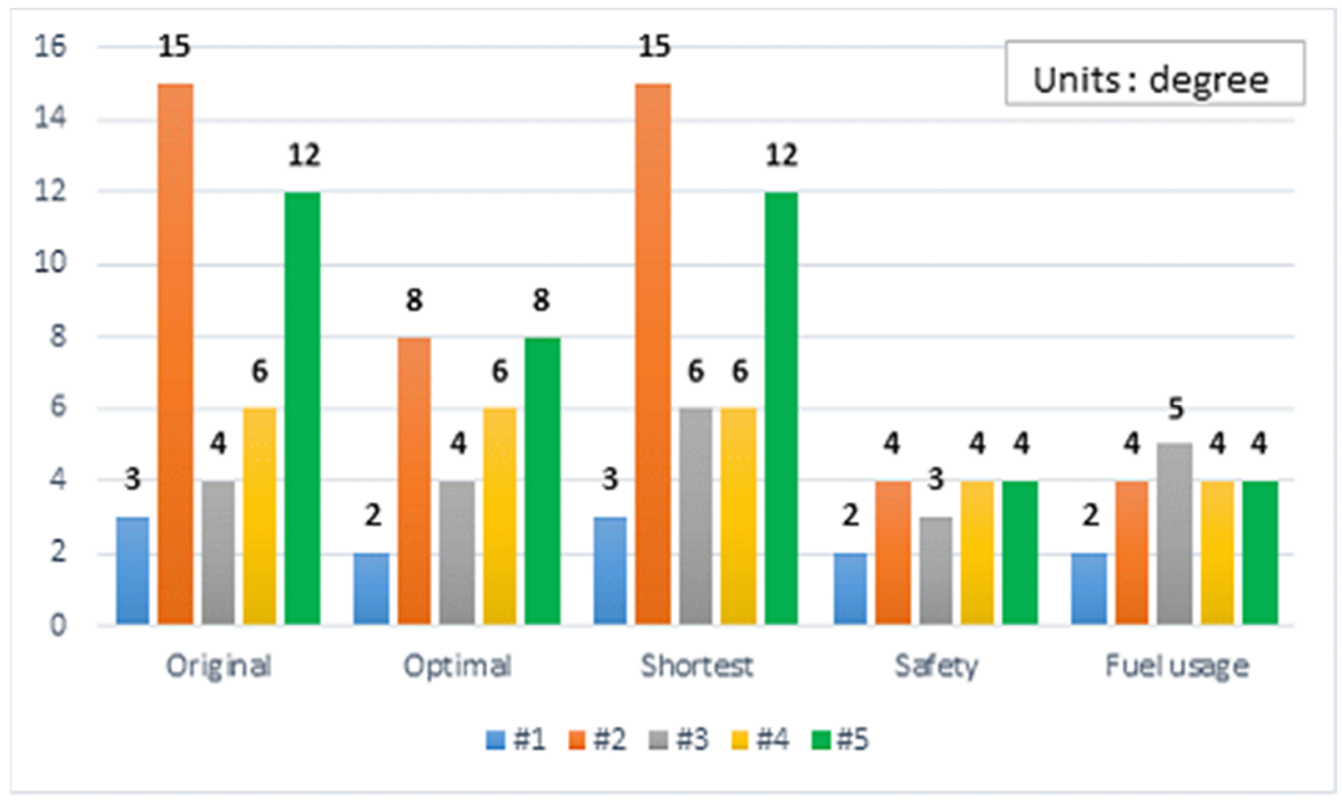

Figure 9. Compare path degree average.

The slope analysis was performed by averaging the slope by cell of each path. Most of the optimal paths over the actual slopes of use were chosen as gentle slopes, whereas the safety and fuel efficiency priority paths presented gentle slopes.

Assuming the same amount of traffic by route, the average speed of travel is as shown in Figure 10.

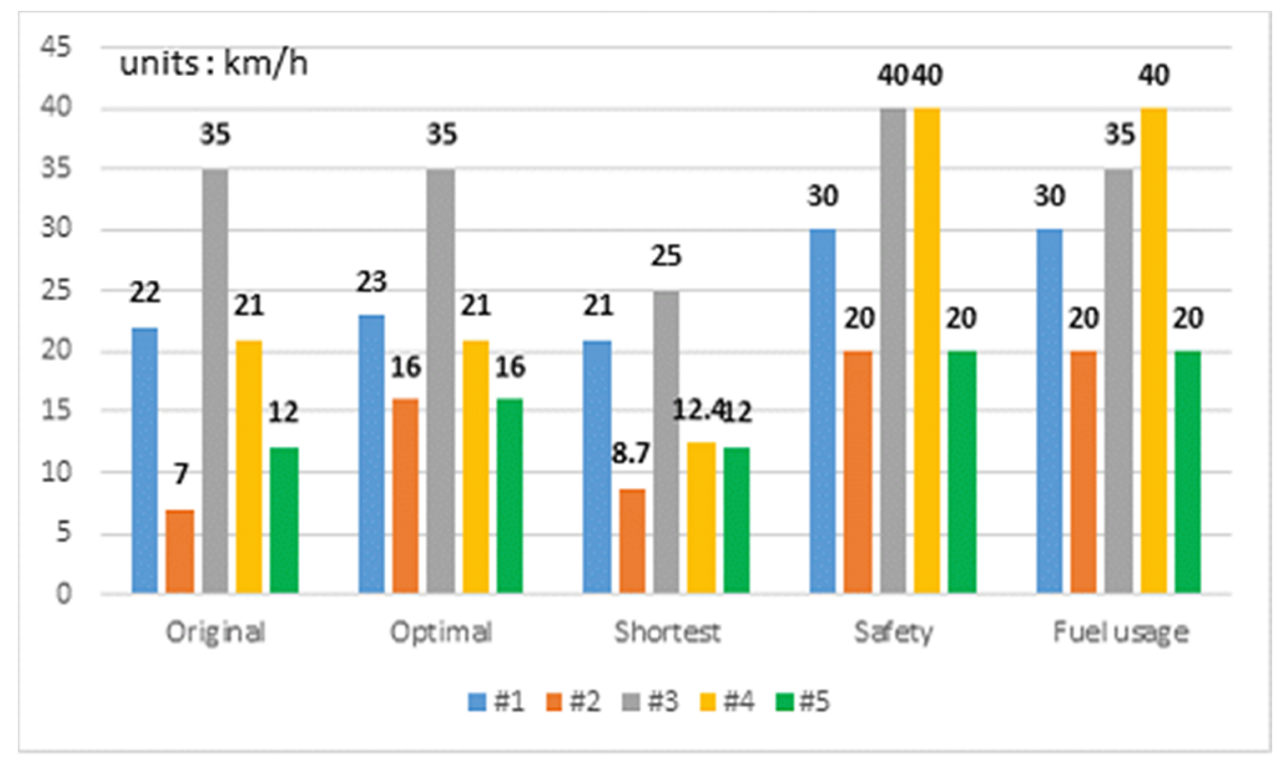

Figure 10. Compare path average speed.

The average speed of travel was the fastest on a safe or fuel-efficient road, and the smallest on the shortest route was due to factors such as high slopes or conditions of the road.

The results of the hourly cost analysis by route are as follows in Figure 11. 


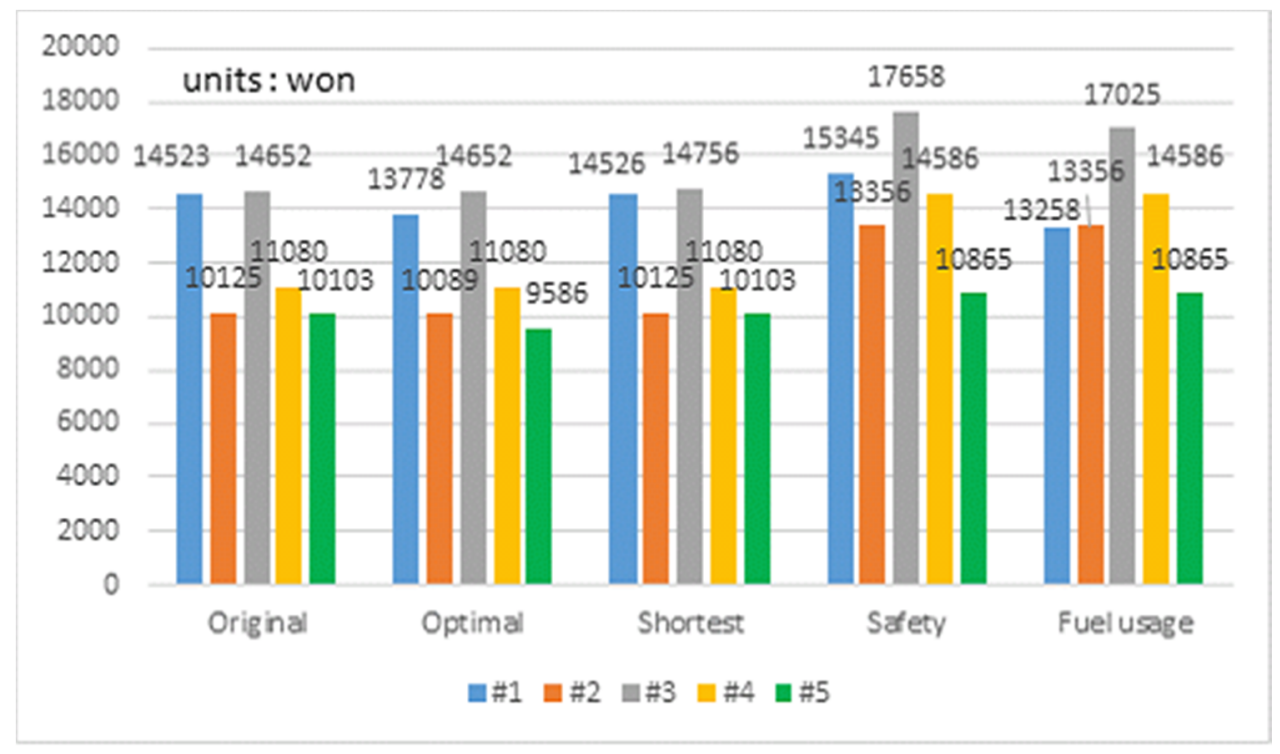

Figure 11. Compare Cost by path.

Cost analysis was conducted on a daily basis based on the amount of work per hour per route, and the average cost of dump per hour as shown in Table 8.

Table 8. Average cost analysis.

\begin{tabular}{cc}
\hline Path & Average Cost \\
\hline Original Path & 12,097 won \\
\hline Optimal Path & 11,837 won \\
\hline Shortest Path & 12,118 won \\
\hline Safety Path & 14,362 won \\
\hline Fuel efficiency Path & 13,818 won \\
\hline
\end{tabular}

As a result of comparing the optimal path by job, the shortest path was given to the equipment, the longest path to fuel efficiency was suggested, and most of the existing routes were similar to or using the same route. Conversely, the velocity of travel was the opposite of the distance traveled. Fuel efficiency is better than unpaved roads, and it is good to use a gentle slope as a route. Conversely, the shortest distance is given as a priority on the shortest distance on the road on which the equipment can be moved. Since the fuel efficiency priority is a good road to drive, the speed of movement is much faster than the shortest route.

However, the cost analysis found the smallest cost in the route that presented the optimal path profile rather than the path that a single indicator was chosen first. The cost analysis calculated the absolute required time based on the daily workload $(8 \mathrm{~h})$ by dividing the required time by the price of the daily dump.

Cost analysis suggested the highest cost of safe routes, which resulted in a significant drop in productivity due to the large number of roads bypassing for safety. At Korean construction sites, the shortest route and the cost were similar in preference to the shortest route. Although there were no outstanding indicators such as distance of movement, slope, and speed of movement, the optimal route was the best in terms of productivity, with the lowest cost. 


\section{Conclusions}

The system to present the route of equipment movement for construction equipment is a system development for construction equipment drivers, and the rate of traffic accidents with ordinary passenger vehicles is high due to speeding and failure to comply with signals when moving dump trucks recently. This is also a major misfortune for construction equipment drivers, but it has led to a drop in productivity throughout the construction site. In addition, dumps do not drive on well-paved roads in the construction site, but they usually use a pavement or a road made up of only old bodies.

Therefore, all sites depend on the number of signals, so drivers are moving equipment. However, the number of signals is not everywhere, and most of them are placed at the entrance of the site, so the equipment driver moves autonomously in areas without the number of signals. As it is operated only by the driver's experience when moving to an out-of-the-field sandpit or a dockyard, the equipment driver is speeding and failing to comply with the signal to complete the work on the same day.

Navigation for general vehicles combines a variety of technologies on the market, reflecting real-time traffic volume to provide the optimal route. However, there was no navigation system for construction equipment, and to develop it, the development was carried out by referring to the current navigation system for general vehicles. First, we analyzed algorithms that present the shortest distance of travel, which is the most basic base algorithm of navigation, and we established factors that should be important when moving equipment through the survey of construction equipment operators.

Through this, an algorithm has been developed that presents the working path of the equipment by considering the weight by dividing the site into grids, separating the driving area and the non-driving area into each cell, and entering the weight value of the driving factor as an attribute value in the driving area.

In order to verify the effectiveness of the algorithm, the actual movement path, optimal algorithm, shortest distance priority, safety priority, and fuel efficiency priority path were presented and compared through simulation. The shortest distance was excellent in terms of travel distance, and the energy efficiency priority road was excellent in terms of travel speed. However, the cost analysis showed that the cost per hour was the smallest when the optimum route was used.

However, in the case of safety-first roads, only factors of road slope and road condition were included, and the result of speeding was that the road was easy to operate, resulting in a high risk of accidents. Although there is a high interest in safety in Korea, it is difficult to quantify the safety level with terrain modeling and simulation due to the constant changes in the traffic conditions and environment around the area. At the construction site, there is a gap between the plan of the field supervisor and the actual driver as the transportation route is planned for the assumption that numerous construction machines are managed and safe to drive. This is because the calculation of construction costs only takes into account invisible safety costs, such as oil costs, labor costs and material costs, and actual costs that are not considered for productivity. To solve this problem, the needs of the two groups of supervisors and drivers were investigated in Optimal Algorithm, and based on this, the optimal path algorithm was created.

The optimal route algorithm presented highly productive routes for safety, including factors such as road conditions, slopes, and the number of operations of the steering wheel.

The results of this study were obtained through simulation using Arena, but the experiment was not carried out by applying it to the actual site. In fact, there is a limit to the application of different results in this study due to environmental factors such as changes in traffic conditions and changes in the environment that have not been quantified. However, I think it will greatly help reduce the accident rate of construction equipment and further increase productivity by utilizing optimal algorithms.

Author Contributions: Designed and performed experiments co-wrote the paper, S.Y.L. supervised the research, carried out the experiment, conceived the original idea. H.J.L. designed experiments, developed the theoretical formalism, performed the analytic calculation and performed the numerical simulation. Both Lee and Lim authors contributed to the final version of the manuscript. All authors have read and agreed to the published version of the manuscript. 
Funding: This research received no external funding.

Conflicts of Interest: The authors declare no conflict of interest.

\section{References}

1. Christian, J.; Xie, T.X. Improving earthmoving estimating by more realistic knowledge. Can. J. Civ. Eng. 1996, 23, 250-259. [CrossRef]

2. Schexnayder, C.; Knutson, K.; Fente, J. Describing a Beta Probability Distribution Function for Construction Simulation. J. Constr. Eng. Manag. Asce 2005, 131, 221-229. [CrossRef]

3. Marzouk, M.; Moselhi, O. Multi objective Optimization of Earthmoving Operations. J. Constr. Eng. Manag. 2004, 130, 105-113. [CrossRef]

4. Park, H.Y.; Tae, Y.H.; Woo, S.K. A Study on the Estimating of the Dump Truck's Travel Speed Based on Analysis of Factors Affecting Earthmoving Operation. Korean J. Constr. Eng. Manag. 2007, 8, 97-105. (In Korean)

5. Ng, S.T.; Zhang, Y. Optimizing Construction Time and Cost Using Ant Colony Optimization Approach. J. Constr. Eng. Manag. 2008, 134, 721-728. [CrossRef]

6. Choi, Y.S.; Seo, J.W. Application of GIS-based Viewshed Analysis for Selecting Optimal Viewpoints and for Evaluating the Sight Distance on a Haul Road in Open-pit mines. J. Korean Soc. Geosyst. Eng. 2008, 45, 1-11. (In Korean)

7. Duke, C.R.; Persia, M.A. Performance-importance analysis of escorted tour evaluations. J. Travel Tour. Mark. 1996, 5, 207-223. [CrossRef]

8. Moselhi, O.; Alshibani, A. Optimization of Earthmoving Operations in Heavy Civil Engineering Projects. J. Constr. Eng. Manag. 2009, 135, 948-954. [CrossRef]

9. Limsiri, C. Optimization of Loader-Hauler Fleet Selection. Eur. J. Sci. Res. 2011, 56, 266-271.

10. Kandil, A. Optimization Research: Enhancing the Robustness of Large-Scale Multiobjective Optimization in Construction. J. Constr. Eng. Manag. 2010, 136, 17-25. [CrossRef]

11. Lim, S.Y.; Kim, S.K.; Ahn, S.H. Development of a Soil Distribution Method and Equipment Operation Models Using Worker's Heuristics. KSCE 2016, 36, 551-564. (In Korean) [CrossRef]

12. Fan, Y. A multi-objective optimization model for energy-efficiency building envelope retrofitting plan with rooftop PV system installation and maintenance. Appl. Energy 2017, 189, 327-335. [CrossRef]

13. Kim, S.K.; Lim, S.Y. A Study on the improvement of a Fleet Management System for Construction Equipment. J. Korean Soc. Civ. Eng. 2017, 37, 1063-1076. (In Korean)

14. Ning, X. A tri-objective ant colony optimization based model for planning safe construction site layout. Autom. Constr. 2018, 89, 1-12. [CrossRef]

15. Lim, S.Y.; Kim, S.K. Productivity analysis using a Fleet Management System for Construction Equipment. KSCE 2020, 40, 87-95. (In Korean)

16. El-Rayes, K.; Kandil, A. Time-cost-quality trade off analysis for highway construction. J. Constr. Eng. Manag. 2005, 131, 477-486. [CrossRef]

17. Hyari, K.; El-Rayes, K. Optimal planning and scheduling for repetitive construction projects. J. Manag. Eng. 2006, 22, 11-19. [CrossRef]

18. Kandil, A.; El-Rayes, K. Parallel genetic algorithms for optimizing resource utilization in large-scale construction projects. J. Constr. Eng. Manag. 2006, 132, 491-498. [CrossRef]

19. Lee, C.; Kim, S. GA-based algorithm for selecting optimal repair and rehabilitation methods for reinforced concrete RC bridge decks. Autom. Constr. 2007, 16, 153-164. [CrossRef]

20. Liu, C.; Hammad, A.; Itoh, Y. Multiobjective optimization of bridge deck rehabilitation using a genetic algorithm. Microcomput. Civ. Eng. 1997, 12, 431-443. [CrossRef]

21. Liu, M.; Frangopol, D. Bridge annual maintenance prioritization under uncertainty by multiobjective combinatorial optimization. Comput. Aided Civ. Infrastruct. Eng. 2005, 20,343-353. [CrossRef]

22. Chan, W.; Hu, H. Production scheduling for precast plants using a flow shop sequencing model. J. Comput. Civ. Eng. 2002, 16, 165-174. [CrossRef]

23. Holland, J.H. Adaptation in Natural and Artificial Systems; University of Michigan Press: Ann Arbor, MI, USA, 1975.

24. Goldberg, D.E. Genetic Algorithms in Search, Optimization and Machine Learning; Addison-Wesley: Reading, MA, USA, 1989. 
25. Burns, S.A.; Liu, L.; Feng, C. The LP/IP hybrid method for construction time-cost trade-off analysis. Constr. Manag. Econ. 1996, 14, 265-276. [CrossRef]

26. Ipsilandis, P. Multi objective linear programming model for scheduling linear repetitive projects. J. Constr. Eng. Manag. 2007, 133, 417-424. [CrossRef]

27. Seo, J.W.; Lee, S.S.; Kim, J.H.; Kim, S.K. Task Planner Design for an Automated Excavation System. Autom. Constr. 2011, 20, 954-966. (In Korean) [CrossRef]

28. Seo, J.W.; Kim, J.H.; Jung, T.H.; Min, J.H.; Hoe, Y.R. The Operating Smart Construction System of Carbon-Reduction Construction Equipments; Research report; KAIA: Anyang, Korea, 2012. (In Korean)

29. Seo, J.W. The Control of Construction Equipments Using ICT and the Technical Development of Smart Construction; Research report; KAIA: Anyang, Korea, 2018. (In Korean)

30. Lee, H.J.; Seo, J.W. Productivity Analysis on Real-time Path Monitoring of Dumps. KSCE 2016, 36, 565-571. (In Korean) [CrossRef]

(C) 2020 by the authors. Licensee MDPI, Basel, Switzerland. This article is an open access article distributed under the terms and conditions of the Creative Commons Attribution (CC BY) license (http://creativecommons.org/licenses/by/4.0/). 